\title{
Community Health Centers (CHCs) Under Environmental Uncertainty: An Examination of the Affordable Care Act of 2010 and Early Medicaid Expansion on CHC Margin
}

\author{
${ }^{1}$ Department of Leadership Studies, School of Leadership and Education Sciences, University of San Diego, San Diego, CA, USA, \\ E-mail:mlam@sandiego.edu \\ ${ }^{2}$ School of Public Policy and Administration, Carleton University, Ottawa, Ontario, Canada, E-mail: \\ NathanGrasse@cunet.carleton.ca
}

\begin{abstract}
:
Nonprofit community health centers (CHCs) are the largest subset of safety net clinics in the United States and, in many vulnerable and underserved areas, act as the only provider of vital health services in the community. The expansion of Medicaid provision under the Affordable Care Act of 2010 led to a fundamental change in the core client demographics of CHCs, with higher income thresholds and single childless individuals now eligible for Medicaid. This expansion of the Medicaid population creates both opportunities and threats that may impact $\mathrm{CHCs}$ ' long term financial sustainability. Accumulating reserves through positive net margins is a managerial tactic that nonprofits can utilize to buffer against environmental uncertainty. This study utilizes data from IRS Form 990s, American Community Survey, HRSA grantee lists, and the Area Resource File to model the differences in net margins between CHCs in early Medicaid expansion and non-expansion states from 2008-2012. Results show higher margins for CHCs in early expansion states compared to non-expansion states, even after accounting for organizational and environmental covariates. CHCs who are HRSA grantees are associated with positive margins whereas those relying more heavily on program revenue show negative margins. Further, CHCs located in counties with higher percentages of persons in poverty also demonstrate reduced margins. This exploratory study contributes to the nonprofit finance literature by highlighting the importance of incorporating contextual variables to deepen our understanding of changes in nonprofit financial health.
\end{abstract}

Keywords: Affordable Care Act, community health centers, early medicaid expansion, financial reserves, net margin

DOI: $10.1515 / \mathrm{npf}-2019-0016$

\section{Introduction}

For over 50 years, nonprofit community health centers (CHCs) have been an integral part of the health care safety net that provide vital services to vulnerable and underserved communities. A core mandate of $\mathrm{CHCs}$ is not just to improve individual health and well-being, but to promote overall community health and to generate economic opportunities for low-income community residents.

While CHCs have been resilient through policy and regulatory changes in the 1990s (Felland et al. 2003), the Affordable Care Act (ACA) of 2010 had the potential to dramatically alter CHCs' operating environments. Specifically, over the long term, it remains to be seen if the Medicaid expansion provision of the ACA provides opportunities for CHCs to capture new clients or leads to increased competition where CHCs continue to serve higher numbers of uninsured patients, while new Medicare enrollees turn to other providers. The long-term viability of a CHC likely depends on its ability to generate and accumulate financial resources. Preliminary reports indicate that, indeed, a greater share of $\mathrm{CHC}$ revenue is coming from Medicaid payments following expansion (Kaiser Family Foundation 2017). Beyond revenue, however, few studies have explicitly modelled changes in CHC net margin, an important measure of long-term financial sustainability (Bowman 2011).

Marcus Lam is the corresponding author.

(cc) BY 2019 Lam and Grasse, published by De Gruyter

This work is licensed under the Creative Commons Attribution 4.o Public License. 
The variation in state decisions to expand Medicaid has allowed for a "natural experiment" condition in which it is possible to study the impact in client composition on CHC margins. This exploratory study uses panel data from IRS Form 990, between 2008-2012, to compare CHCs in five early expansion states and the District of Columbia to non-expansion states. Results indicate that CHC margins are higher in these early expansion states, which supports the hypothesis that CHCs have been, at least initially, able to take advantage of the opportunities stemming from the Affordable Care Act. This study makes an important contribution to the nonprofit financial management literature by examining how environmental changes - enactment of a new public policy leading to changes in client composition - can potentially affect an important measure of financial sustainability.

The paper proceeds as follows: the next section briefly reviews Galaskiewicz and Bielefeld's (1998) organizational change framework as a way to understand why organizations choose specific tactics, before we look to the nonprofit financial management literature in order to demonstrate that the accumulation of reserves, through positive net margins, is a useful strategy in uncertain environments. Next, we discuss the community health center (CHC) movement and the significance of CHCs in serving vulnerable communities. This leads to a discussion of the Medicaid expansion provision of the Affordable Care Act of 2010 and how this may impact CHC margins. Our data, variables, and analysis procedure will be reviewed in the methods section. This is followed by the presentation of our results, a discussion of the implications of our findings for policy and practice, limitations, areas for further research, and the conclusion.

\section{Accumulation of Reserves as a Tactical Response to Environmental Uncertainty}

Nonprofits operate in uncertain environments. Environmental uncertainty may come from changes in public policy or professional norms (regulatory and institutional environment), client demands and preferences (market environment), or increases/decreases in competitors (organizational environment) (Shea and Hamilton 2015). Bigelow and Stone (1995) outline a model for an organization's responses to changes in the institutional and regulatory environments that can range from compliance (actual or symbolic) to resistance, depending on internal administrative and coalition values and skills, as well as external relationships and dependencies. For changes in market and organizational environments, response can include streamlining expenses to improve efficiencies, attempts to capture new revenue sources, increased marketing, or mergers and partnerships with other organizations (Galaskiewicz and Bielefeld 1998). How organizations respond may largely depend on whether an organization is more sensitive to institutional or market forces.

We draw from Galaskiewicz and Bielefeld (1998) organizational change framework to understand accumulating resources as a useful strategy in uncertain environments. Galaskiewicz and Bielefeld (1998) introduced the "niche" concept as a way to examine the alignment between organizational strategies and environment. An organization's niche is the space - not necessarily geographically bounded - in which organizations compete for resources. Niches are segmented along areas of "structural equivalence" (p. 13). For example, organizations share the same niche if they compete for similar resources such as capital, sales, technology, or labor (p. 13). Acquisition of resources, as a key driver of organizational strategy and tactics, must be aligned to the conditions and demands of its respective niche in order to procure both resources and legitimacy.

Organizations operating in the health sector, such as general hospitals and health clinics, exist in niches that emphasize both output and process controls (Galaskiewicz and Bielefeld 1998). That is, in order to procure resources, health care organizations must compete along service quality and costs (output controls) as well as adhere to regulatory requirements and professional norms of conduct (process controls). ${ }^{1}$ As such, nonprofits that provide health services (i. e. surgeries, health exams, dental procedures, x-rays, etc.) can be referred to as commercial nonprofits as they rely heavily on fees (versus donative or grant income) and paid employees (versus volunteers) as core resources. Managerial tactics such as improving cost efficiencies, enhancing financial and quality controls, or realignment of executive and support positions, are particularly salient for "commer-

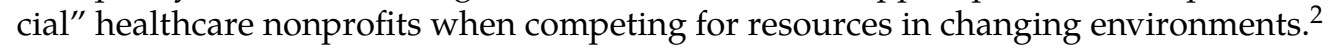

A key managerial tactic in response to environmental uncertainty is to build reserve funds to be used in the case of resource scarcity or loss. The accumulation of reserves by nonprofits as a buffer against financial vulnerability is a well-documented tactic in the nonprofit finance literature (Calabrese 2012, 2013). This is especially critical for nonprofits in underserved areas where they may be more financially vulnerable (Lam and McDougle 2016). Nonprofits build unrestricted reserves through the gradual accumulation of excess revenue over expenses. This measure is referred to as a "profit margin" or simply as "margin" and commonly calculated by dividing the change in net assets (revenue minus expenses) over total revenue. Nonprofit finance scholars such as Tuckman and Chang (1991) define a positive "margin" as an explicit measure of financial stability; sim- 
ilarly, Greenlee and Bukovinsky (1998) refer to a "savings indicator" as a measure of resource adequacy; and Bowman (2011) operationalizes "return on assets" as a crucial measure of long-term financial sustainability. ${ }^{3}$

Additionally, studies utilizing "margin" as a predictor of financial vulnerability find consistent and significant results (see Hager 2001 for arts organizations; Greenlee and Bukovinsky 1998; Clemenson and Sellers 2013, for social services). In the health sector, operating and financial margins are also used to measure the financial viability of hospitals (Bazzoli, Fareed, and Waters 2014; Antonisse et al. 2018), trauma centers within safety-net hospitals (Knowlton et al. 2018), and safety-net health systems (Chokshi, Chang, and Wilson 2016). Below, we rely on margins as a measure of the viability of CHCs.

\section{Community Health Centers}

Stemming from the civil rights movement and Lyndon Johnson's War on Poverty, the CHC program was established in 1965 to provide federal grants for health projects serving the poor as well as for projects that addressed the overall health of communities (Bailey and Goodman-Bacon 2015; Katz et al. 2011; Henry 2015; Fiscella and Jack Geiger 2014). Funding sought to improve access to primary health services by supporting programs with ancillary services, such as home health care, mobile units, transportation services, English translation services, and clinic sites located in underserved communities (Bailey and Goodman-Bacon 2015).

At present, $\mathrm{CHC}$ are the largest subset of "safety-net" providers in the nation whose mission is to provide services for the uninsured, underinsured and other socio-economically vulnerable populations (Kaiser Family Foundation 2017; Bailey and Goodman-Bacon 2015; Fiscella and Jack Geiger 2014). There were 1,375 CHCs in 2015, providing care to 24.3 million patients and almost $17 \%$ (1 to 6) of all Medicaid enrollees (Kaiser Family Foundation 2017; NACHC 2013). Over $70 \%$ of patients served by CHCs earn $<100 \%$ of the federal poverty level, and $>50 \%$ are racial/ethnic minorities (NACHC 2013). CHCs also provide business development opportunities as employers, having created 189,000 jobs for disadvantaged neighborhoods in 2009, requiring patients to serve as board members, and community development through intervention programs to address the social, economic, and environmental determinants of health problems (McAlearney 2002; Kotelchuck, Lowenstein, and Tobin 2011). In short, CHCs are a vital resource for underserved and vulnerable communities.

Virtually all CHCs are incorporated as 501c(3) nonprofit organizations and, as such, are subject to the basic tenets of proper nonprofit financial management practices. One such basic tenet is to generate enough resources in order to cover expenses and break even, or to generate a surplus in excess of expenses, which may then be saved to build a reserve or savings fund. As Felland et al. (2003) note in their study of the resiliency of the health care safety net, CHCs adopt a "no margin, no mission" principal (p. 13).

The health care market differs from competitive markets for traditional goods and services in several respects. First, prices for health services are not generally established by consumer demand but established centrally by state or federal agencies (Allard and Smith 2014). Prices that are charged for certain health care services and procedures often do not cover the full costs of production (Allard and Smith 2014; Walker and Osterhaus 2010). Payments for services often do not come directly from the patients but from third party insurers, such as private insurance companies or Medicaid and Medicare programs. As such, there ensues a waiting period between when services are provided (i. e. costs incurred) and when expenses are reimbursed by the third-party insurer. In addition, barriers to entry in the health care market may be more difficult as certain states require Certificates of Need (CON). ${ }^{4}$ This may be a significant barrier which has been found to curtail the expansion and establishment of health facilities, with substance abuse providers as an example (Noh and Brown 2018).

These unique aspects of the health care market, combined with serving impoverished populations, may negatively impact CHCs' long term financial sustainability. Medicaid patients make up nearly half of all CHC patients ( $49 \%$ in 2015) with the uninsured making up a quarter ( $24 \%$ in 2015) (Kaiser Family Foundation 2017). Revenue from Medicaid payments is the largest percentage of total CHC revenue (44\% in 2015), followed by Medicare (7\%), private insurance (9\%), Section 330 grants (18\%), and state/local/private grants and contracts (11\%) (Ibid).

Evidence from prior studies of $\mathrm{CHC}$ finances suggests that, on average, $\mathrm{CHCs}$ do not earn large margins and may be left financially vulnerable under managed care arrangements (McAlearney 2002; Henderson and Markus 1996; Schauffler and Wolin 1996). More recent estimates of CHCs' finances indicate that, on average, centers have very low (or negative) margins, with revenue exceeding expenses by $<1 \%$ from 2001-2008 and between 2-5\% from 2009-2011 (NACHC 2013). This estimate is similar to other studies that have found safety net providers, including hospitals, have low operating margins (Chokshi, Chang, and Wilson 2016; Knowlton et al. 2018).

With little ability to save and generate income reserve, it may be difficult for $\mathrm{CHC}$ s to expand services, plan for unexpected contingencies, or cope with major disruption in their revenue streams. As mentioned previ- 
ously, underlaying the ability for organizations to respond to their external environmental is an organization's financial sustainability. Long term financial sustainability, measured by positive net margins, is crucial to an organization's ability to operate and respond to external shocks (Bowman 2011). At the policy level, understanding the changing financial condition of CHCs, the potential shifting demographics of the patients served, and the impact of the ACA on their services and mission, is critical to evaluating the Affordable Care Act's success in serving low-income populations.

\section{Affordable Care Act}

The Affordable Care Act (ACA) of 2010 afforded health insurance to millions who were previously uninsured, thus offering individuals and families a degree of financial security (Cantor et al. 2012; Allen et al. 2017; Antonisse et al. 2018). At the same time, the ACA also changed the health care market by allowing for more choice of health insurance plans as well as health care providers (Doonan and Katz 2015). The impact of these changes on individual health outcomes, individual health-seeking behavior, individual health insurance usage behavior, service quality, and financial stability of safety-net health providers is just beginning to be understood (Kaiser Family Foundation 2018).

First, the impact of the ACA on individual health insurance coverage is clear, as studies indicate CHCs in Medicaid expansion states serve a greater percentage of Medicaid patients than those in non-expansions states, and fewer uninsured patients (Han, Luo, and Ku 2017; Huguet et al. 2017; Miller and Wherry 2017). Service utilization also differed as CHCs in expansion states experienced increases in new patients, visits for preventative and mental health services, and limited-service visits (Hoopes et al. 2016; Han, Luo, and Ku 2017). At the state level, newly enrolled Medicaid patients had higher rates of primary care, behavioral, mental health visits, and increased demand for non-emergency ambulatory care (DeVoe et al. 2015; Ku et al. 2011). Finally, descriptive reports of the impact of expansion on $\mathrm{CHC}$ finances indicate that $\mathrm{CHCs}$ in Medicaid expansion states report higher revenue, largely from Medicaid payments (Kaiser Family Foundation 2017).

Given that Medicaid patients account for a large share of CHC patients, and that Medicaid reimbursements are the largest percentage of total revenue for $\mathrm{CHCs}$, the Medicaid expansion provision of the ACA may have the most significant impact on CHC finances (Choski et al. 2016; Kaiser Family Foundation 2017). Under the ACA, the Medicaid income-based eligibility increased to $138 \%$ of the federal poverty level (FPL) and categorical based eligibility came to include a large subset of the population that were previously ineligible, namely, single, childless adults (Katz et al. 2011). Since the passage of the ACA in 2010, five states (California, Washington, New Jersey, Connecticut, Minnesota) and the District of Columbia, opted for early expansion (Sommers et al. 2013). As of May 2019, 37 states including the DC have opted for Medicaid expansion and 14 states have not (Kaiser Family Foundation 2019). This variation in state policies on Medicaid expansion allows for a "natural experiment" condition to compare the financial sustainability of CHCs located in Medicaid expansion versus non-expansion states.

The expansion of Medicaid presents both opportunities and threats to CHCs (Fiscella and Jack Geiger 2014; Chokshi, Chang, and Wilson 2016). First, expansion will increase the total number of Medicaid eligible beneficiaries, with CHCs seeing a higher percentage of Medicaid patients in expansion versus non-expansion states (Han, Luo, and Ku 2017; Huguet et al. 2017; Miller and Wherry 2017). A larger clientele will translate to higher revenues and, assuming that costs remain unchanged, higher margins. Estimates of CHC revenue appear to find partial support for this hypothesis as total revenue from Medicaid increased from $40 \%$ in 2013, one year prior to ACA expansions, to 44\% in 2015 (Kaiser Family Foundation 2017). The impact on margins, however, is still unclear.

On the other hand, CHCs may face competition as a larger Medicaid beneficiary pool may attract new providers or entice current providers to expand services to new Medicaid beneficiaries. As "commercial" nonprofits, CHCs are more likely to compete with for-profit providers - and other nonprofits - as market demand increases (Galaskiewicz and Bielefeld 1998). In fact, studies have documented the equivalence of certain health care services and outcomes between CHCs and other providers (Evans et al. 2015; Bruen et al. 2013). In addition, if the newly eligible Medicaid beneficiaries (i. e. childless adults up to $133 \%$ of FPL) are healthier and do not choose $\mathrm{CHC}$ s for primary health care services, this may lead to a two-tiered system in which CHCs will continue to serve the most vulnerable populations, with greater health needs, without capturing new Medicaid patients. The result of this second potential scenario is a decrease in revenue with increased costs, leading to lower net margins. Of course, the likelihood of either of these scenarios is dependent on a number of factors including, but not limited to, whether a state has a managed care option, certificates of need in place, and demands for services (Katz et al. 2011; Noh and Brown 2018). 
This study will contribute to the literature in several ways. Foremost, it examines net margins, an important measure of long-term financial sustainability (Bowman 2011), rather than total revenue or total expenses (Kaiser Family Foundation 2017). This study also examines several contextual variables and will contribute to an understanding of the relationship between changes in environmental conditions and financial sustainability. Finally, this study samples a more comprehensive population of CHCs using data from the IRS rather than from the Uniform Data System (UDS). While the UDS is an important source for data on CHC services, health outcomes, and patient characteristics, it provides only limited data on CHC finances. Thus, a study of CHC finances should, arguably, utilize data, such as IRS Form 990, which explicitly accounts for financial constructs. The next section presents data sources and description and operationalization of the primary variables of interest.

\section{Methodology}

\subsection{Data Sources}

This study incorporates data from three sources: National Center for Charitable Statistics (NCCS), the American Community Survey, 1-year data, and the Health Resources and Services Administration (HRSA) grantee list and Area Resource File. Organizational data for the outcome variable and covariates are drawn from IRS Form 990 Core Trend Files from the NCCS for 2008-2012. Based on 2008 IRS guidelines, nonprofits with gross receipts of $\$ 25,000$ (shifting to $\$ 50,000$ in 2010) or more are required to file Form 990 with the IRS annually. IRS Form 990 is self-reported and contains financial information from the organization's operating statement, balance sheet, and functional expenses. CHCs are identified in the dataset using the National Taxonomy of Exempt Entities (NTEE) and nteeIRS code E32 for "Community Clinics." In 2011, there were approximately 1,706 nonprofits identified as community clinics in the dataset. The IRS files contain a broader list of community clinics compared to the data from the HRSA database. Organizations in the IRS Core files include FQHCs, FQHC look-alikes, and a smaller number of organizations that were neither. A comparison between the list of organizations in the Core trend file against the list of CHCs in the HRSA database for one county (San Diego), revealed that approximately $89 \%$ of the organizations in the HRSA list were also captured in the Core trend file list. ${ }^{5}$

The Core trend files for 2008-2012 is a panel dataset for "E32" community clinics and contains 8,534 organization year observations ( 1,700 observations per year). Of the 8,534 observations, $73.3 \%$ had observations for all five years, $14.3 \%$ had observations four of the five years, $5.3 \%$ had observations for three of the five years, $4.1 \%$ had observations for two of the five years, and $3.0 \%$ had observations for only one year. Thus, the data is an unbalanced panel set.

HRSA grantee data for award years 2008-2012 was drawn from the HRSA data warehouse. ${ }^{6}$ Data at the county level for percentage Medicaid beneficiaries is drawn from the American Community Survey, 1-year data, and downloaded from the Integrated Public Use Microdata Series (IPUMS) website for 2008-2012. Data for the number of hospitals and federally qualified health centers at the county level was drawn from the HRSA's Area Resource Files, 2013-2014.

\subsection{Outcome Variable}

While nonprofit financial health can be measured along several dimensions, such as liquidity, solvency, and profitability or net margin (see Bowman 2011 for a fuller discussion of financial capacity and sustainability), we focus only on net margin as a fundamental measure of financial health as supported by McAlearney (2002), Knowlton et al. (2018), Bazzoli, Fareed, and Waters (2014), and Chokshi, Chang, and Wilson (2016), who have examined the financial health of safety-net providers.

Net margin, a profitability measure, is an indicator of whether an organization's revenue is sufficient to cover its expenses. We use a modified version of net margin, taking the ratio of total revenue divided by total expenses. This was preferred over taking net margin divided by total expenses, given that we log the outcome variable; this transformation would result in undefined values when transforming negative total margins, representing organizations operating in deficit. Thus, the ratio of total revenue over total expense transforms deficits (defined as ratios less then 1) into negative values when logged, while values greater than 1 (representing surplus) remain positive when logged (see Table 1 for summary statistics). ${ }^{7}$ 


\subsection{Primary Independent Variable}

The primary independent variable is the location of CHCs in an early expansion state. Following passage of the ACA in 2010, only five states and the District of Columbia voted for early Medicaid expansion, as written in the ACA (Sommers and Epstein 2013). These states were California, Minnesota, New Jersey, Connecticut, and Washington. The "expansion" variable was measured as dichotomous ( $1=$ location in expansion state; $0=$ location in non-expansion state). In addition, this variable was treated as time-variant as expansion did not occur in any state in the first two years of the dataset (2008 and 2009).

\subsection{Organizational Covariates}

As a control for organizational size, we include total assets (time invariant). As a measure for the percentage of total revenue from Medicaid payments, we include "program revenue" (IRS Form 990, Part I, line 9) as a covariate (time variant). We calculate the "program revenue" covariate as the percentage of program revenue over total revenue. Finally, we include an indicator of receipt of any HRSA key program grant between 20082012. Receipt of a HRSA grant is used as a proxy for FQHC designation. Given that this designation confers with it a range of benefits, centers that are designated FQHCs may be able to weather changes in market conditions more successfully. Receipt of a HRSA grant is measured as a dichotomous variable $(1=$ yes; $0=$ no $)$ and is time-invariant. This HRSA grantee list was joined with the Core trend file using the organization's employer identification number (EIN).

\subsection{County Covariates}

As measures of competition, the density of hospitals and FQHCs per 10,000 persons were included as covariates. The number of hospitals was available only for two years (2010 and 2011) and the number of FQHCs was only available for four years (2010-2013) from the HRSA Area Resource File. We took the average of these values and divided it by the average population estimates for the same years in each county to obtain a per capita value. Next, we multiplied this per capita value by 10,000 . Thus, these two measures, operationalized as the number of hospitals and FQHCs per 10,000 persons are time-invariant.

Two covariates were considered as measures of need and demand for services. The first is percent persons in poverty, drawn from the Area Resource File. Populations in poverty may have higher demands for services and incur higher service costs and thus lower margins. The percentage of those in poverty is measured as the average of the percentage of the population in poverty over total population, averaged across the five years under study and treated as time invariant. The next measure of demand is percentage of Medicaid beneficiaries in the county and state. Given that Medicaid beneficiaries make up a large share of CHC total patient mix, higher percentages of Medicaid beneficiaries may translate to higher revenues and potentially higher margins. We calculated this variable as the percentage of the population with Medicaid insurance over total population (time-variant).

\section{Analysis Procedure}

We examine associations between $\mathrm{CHC}$ margins and Medicaid expansion using a system generalized method of moments (GMM) dynamic panel models. These models (Formula 1) account for the following: a dependent variable that is partly a function of its past values $\left(\beta y_{i t-1}\right)$, organization-specific unobserved characteristics $\left(\alpha_{i}\right)$, time-invariant characteristics $(\beta z i)$, time-variant characteristics $\left(\beta x_{i t}\right)$, idiosyncratic shocks $\left(\mu_{i t}\right)$, and time effects $\left(\lambda_{t}\right)^{8}$

$$
y_{i t}=\alpha_{i}+\beta y_{i t-1}+\beta z_{i}+\beta x_{i t}+\mu_{i t}+\lambda_{t}
$$




\section{Results}

\subsection{Summary Statistics}

Table 1 presents summary statistics of all variables at baseline (2008) and the percentage change in mean and median values between 2008 and 2012. On average, CHCs had positive margins with median total revenue 1.03 times total expenses. Overall, margins remained relatively stable from 2008-2012, with median values ranging between 1.02 and 1.03. Approximately $36 \%$ of organizations were HRSA grantees, and program revenue accounted for $43 \%$ of total revenue in 2008 with a $1 \%$ decrease in the mean and $3 \%$ decrease in the median values between $2008-2012$.

At the county level, there were, on average, approximately 0.26 hospitals and 0.30 federally qualified health centers (FQHCs) per 10,000 persons. Approximately $10 \%$ of counties and $17 \%(303$ of 1,737$)$ of organizations were located in one of the six early Medicaid expansion states in 2011. At the county level, data for percentage of Medicaid was only available for a limited number of counties from the American Community Survey 1-year data. The median percentage of the population was $17 \%$ and this increased by $19 \%$ between 2008 and 2012 . Similarly, at the state level, the percentage of the population on Medicaid was $15 \%$ with a $15 \%$ increase between 2008 and 2012. Table 2 presents a correlation table for all variables and across all years in the model. 


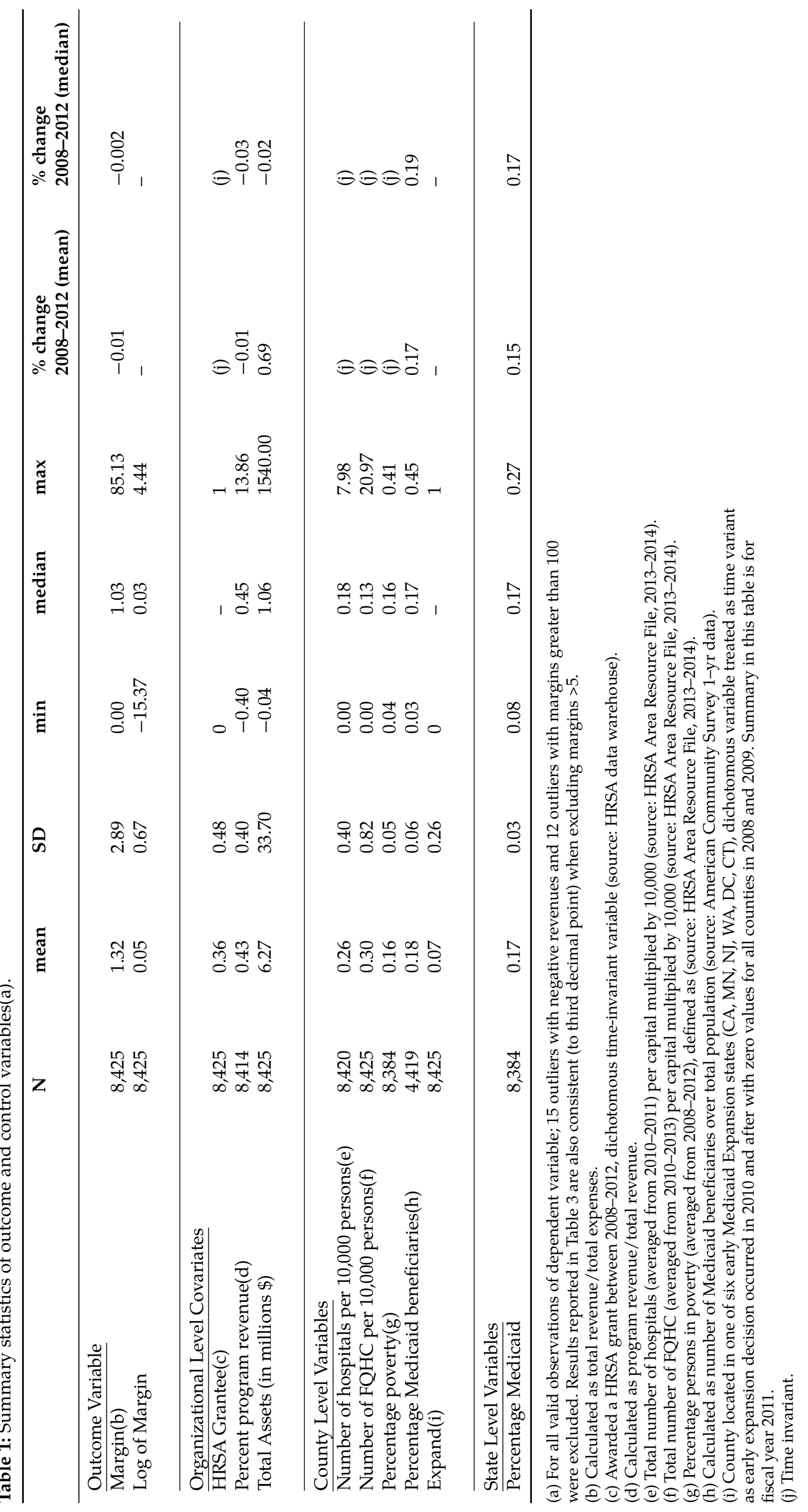


Table 2: Correlation matrix, for all observations across all years (2008-2012).

\begin{tabular}{|c|c|c|c|c|c|c|c|c|c|c|c|}
\hline & $(\mathrm{n}=8,334)$ & (1) & (2) & (3) & (4) & (5) & (6) & (7) & (8) & (9) & (10) \\
\hline$(1)$ & Margin & 1 & & & & & & & & & \\
\hline (2) & Expansion & -0.01 & 1 & & & & & & & & \\
\hline (3) & Medicaid Percent State & -0.04 & 0.14 & 1 & & & & & & & \\
\hline$(4)$ & HRSA Recipient & -0.01 & 0.01 & 0.04 & 1 & & & & & & \\
\hline (5) & FQHC Density & -0.02 & -0.03 & 0.02 & 0.16 & 1 & & & & & \\
\hline (6) & Hospital Density & -0.01 & -0.07 & -0.11 & 0.01 & 0.09 & 1 & & & & \\
\hline (7) & Poverty Percent & -0.04 & -0.10 & 0.21 & 0.14 & 0.19 & 0.08 & 1 & & & \\
\hline (8) & Program Revenue Percentage & -0.17 & 0.05 & 0.08 & 0.23 & 0.07 & 0.08 & 0.05 & 1 & & \\
\hline (9) & Total Assets & 0.00 & 0.07 & 0.08 & 0.07 & -0.01 & -0.03 & -0.02 & 0.12 & 1 & \\
\hline (10) & Fiscal Year & -0.04 & 0.29 & 0.33 & -0.03 & -0.01 & 0.00 & -0.02 & -0.01 & 0.04 & 1 \\
\hline
\end{tabular}

\subsection{Results}

Models 1 to 5 of Table 3 demonstrate the impact of Medicaid expansion on CHCs' margins, with the variable for Medicaid expansion significant and positive in all models. The effect of expansion is measured in the resulting percentage change in the organization's margins, accounting for a slight auto-regressive trend in the dependent variable. ${ }^{9}$ This varies slightly across models, $5.2 \%$ in our parsimonious model (Model 1), $5.74 \%$ in our model introducing organization-level covariates (Model 2), $3.60 \%$ when county-level covariates are introduced (Model 3-with a lack of Medicaid data for some counties reducing n), 5.72\% when state Medicaid data replace county averages (Model 4), and 5.76\% when taking into account density of FQHCs and hospitals as a proxy for competition (Model 5). These results demonstrate a substantively and statistically significant positive influence of Medicaid expansion on CHC margins. ${ }^{10}$ We also find that three other variables influence CHCs' margins. At the organizational level, both HRSA grant funding and reliance on program service revenues influence margins. HRSA grant recipients have margins that are dramatically higher than their peers (ranging from $15.62 \%$ in Model 3 to $21.25 \%$ in Model 5). 


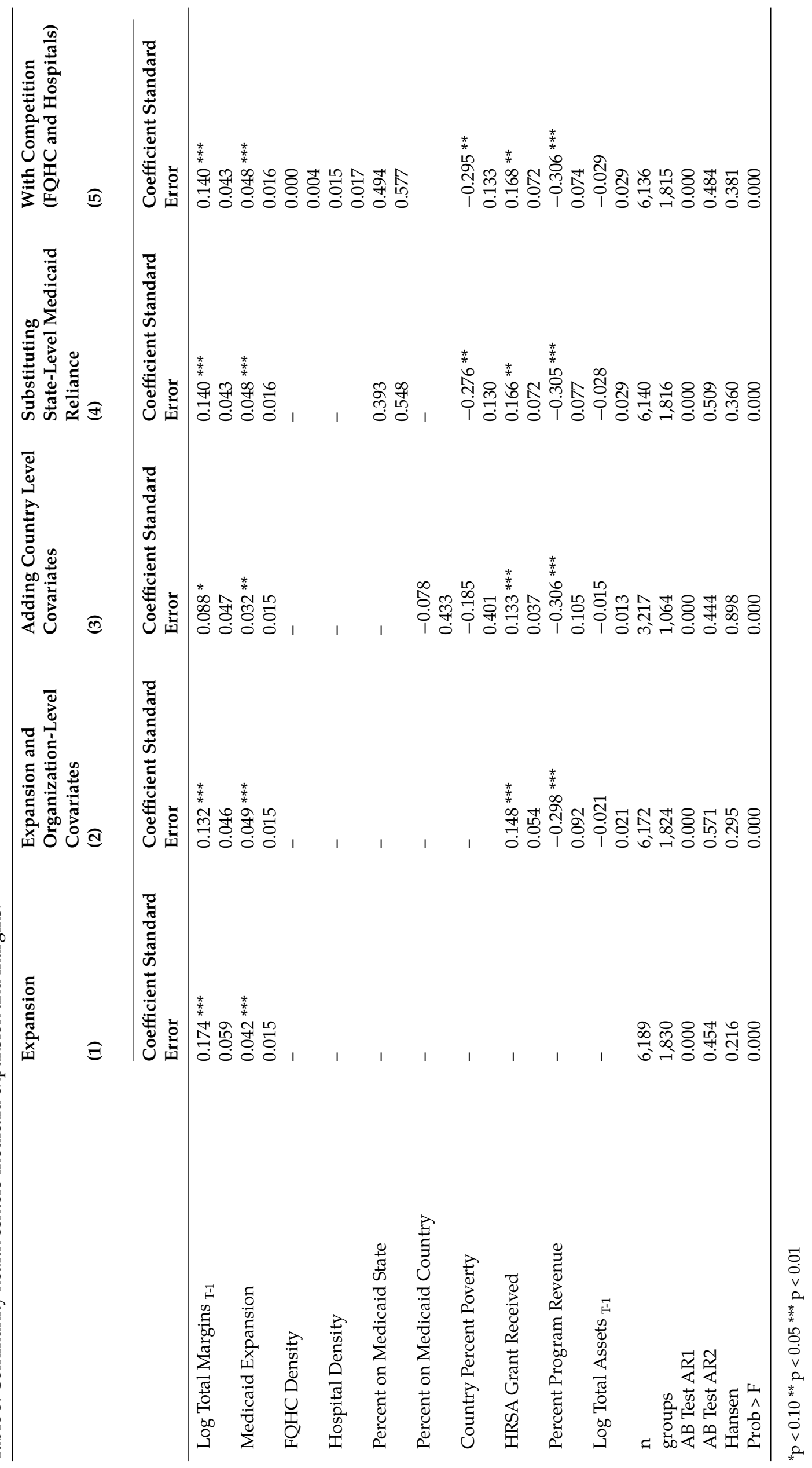


We find that increased reliance on program service revenue is associated with lower margins, with a $1 \%$ change in an organization's reliance on program revenue resulting in an approximate $-0.35 \%$ change in an organization's margins. We suspect this is a function of CHCs' program revenues failing to cover core expenses, with revenue in excess of these expenses coming from contributions or government grants (substituting contributions percentage results in a positive but statistically insignificant coefficient). ${ }^{11}$

At the county level, the percentage of the population living below the poverty line negatively associates with margins, with a $1 \%$ increase in percentage in poverty resulting in a $-0.28 \%$ change in the $\mathrm{CHC}^{\prime}$ 's margins in Model 3 and $-0.30 \%$ change in Model 5 . Altogether, these results demonstrate that the financial condition of CHCs is influenced by state policy, organizational-level factors, and the service populations in which they operate.

\section{Discussion}

The Medicaid expansion provision of the ACA might have presented either threats or opportunities for CHCs. Results from this exploratory study suggest that Medicaid expansion resulted in higher net margins for these organizations. This effect is present even when accounting for organizational and environmental differences between organizations.

At the county level, poverty is associated with negative margins. This finding is consistent with studies of the social determinants of health (Alvarez et al. 2015), which may lead to higher cost of care expected due to negative health outcomes manifested in adverse conditions (stress, poor nutrition, etc.). The absence of client insurance for those living in poverty and potential lack of discretionary income to pay may also be reducing CHCs' margins in these counties, as would be a reduced tendency to access preventative care services (Taubman et al. 2014).

At the organizational level, both HRSA grant funding and program service revenues associate with CHCs' margins in different ways. It is not surprising that CHCs who are HRSA grant recipients, a proxy for FQHC designation, have higher margins. Federal FQHC designation confers a myriad of benefits, including enhanced reimbursements from Medicaid and Medicare, discounts for pharmaceuticals, as well as grants for capital and operational expenses, amongst others (Katz et al. 2011). These enhanced benefits may allow FQHCs a stronger foundation upon which to provide services or sustain environmental shocks.

For program revenue, the negative relationship may be partially explained by a number of alternatives. First, this finding supports the argument that funders of nonprofit service providers often do not pay for the full cost of service production (Walker and Osterhaus 2010). For the health sector in particular, prices for certain procedures are established at the state or federal level and are decoupled from the expenses incurred by providers at the ground level. Thus, higher program service revenue in the form of third-party reimbursements (i. e. Medicaid) may mean higher administrative costs, longer wait times for payment, and non-competitive and below market prices for services rendered.

Additionally, there is also a waiting period or gap between service provision and service payment by third party insurers such as Medicaid. To supplement this payment gap, as well as to cover the full cost of service, CHCs may need to fund raise alternative revenue sources such as grants or individual donations. As such, the negative coefficient for program revenue may be a reflection of the need for a diversity of revenue streams, although further analysis is needed.

Galaskiewicz and Bielefeld's (1998) model of organizational change reminds us that organizations operate in niches with varying process and output controls. Health care nonprofits operate in niches where both output and process control are dominant. The value of this insight is that managerial tactics, such as accumulation of financial reserves through positive net margins, can only advance nonprofits so far in acquiring resources and legitimacy. Political or legitimation tactics, both internal and external, such as developing policies based on regulatory mandates (i. e. affirmative action, whistle blower, etc.), advocacy, re-branding, or securing funding from reputable institutions, are just as important. If so, low margins may not be immediately worrisome if nonprofits are also politically savvy enough to acquire other resources in order to weather environmental changes.

\section{Limitations and Areas for Further Research}

One important limitation of this study is that we only examine data for five early expansion states and the District of Columbia. The full implementation of Medicaid expansion occurred in 2014, two years after the final observation year of this study. Thus, the true impact of Medicaid expansion on net margin may not be fully 
realized in the years of this study. This may be true if there are both lagged and "spill-over" effects due to spatial or geographic adjacency between expansion and non-expansion states.

There are also limitations with the IRS Form 990 data as is well documented in prior studies utilizing this dataset. Firstly, as the data is self-reported this may lead to inaccuracies, although Froelich, Knoepfle, and Pollak (2000) report consistency between IRS Form 990 and audited financial statements. Secondly, the use of NTEE codes designated as "E32 - Community Clinics" may not capture all FQHCs. Given that NTEE codes are based on an organization's stated mission, this filter may invariably miss FQHCs that provide multiple programs, including social and health services, and thus can be categorized as "human service organizations" rather than "community clinics" (see footnote \#5).

Additionally, as Allard and Smith (2014) point out, the "program revenue" line item on the IRS Form 990 (Part I, line 9) captures revenue not only from Medicaid, but also from private insurance, Medicare, out-ofpocket payors, and other earned income strategies (i. e. selling food in an inhouse coffee shop). Thus, we cite prior studies documenting the large percentage of revenue from Medicaid (Kaiser Family Foundation 2017) and make an assumption that this also applies to our data. However, we acknowledge that the "program revenue" measure used in our study may indeed have other, non-Medicaid revenue, the exact percentages of which remain unknown.

Finally, the large difference in mean (1.33) and median (1.02) margin values in Table 1 for 2008 points to outliers in our data. While we exclude 27 extreme outliers, there remains variation in the dataset as is also evidenced by the standard deviation (2.52) (the 25th and 75th percentile values for 2008 are 0.96 and 1.15 respectively). Nevertheless, we believe that a log transformation of the outcome variable is appropriate to address the variation. Additionally, mean and median values are closer (1.09 vs. 1.03$)$ when excluding margin values greater than 5 and results (not presented) are consistent with Table 3. This suggests that the skewness in the distribution of margins, does not substantively impact our findings.

A follow up study will limit the analysis to just FQHCs and look-alikes as listed in the UDS. It will also examine a longer and more recent time period (2005-2015) to see if the initial findings from this exploratory study is consistent with more current data.

\section{Conclusion}

The uncertainty created by the expansion of Medicaid and its impact on CHCs' financial resources remains to be determined. However, there does appear to be contextual effects at the organization and county level that may moderate the impact of Medicaid expansion, such as the population in poverty in a given area or the receipt of prior HRSA funding. Without adequate reserves, liquidity, or other methods, including borrowing or access to lines of credit to cover deficits, CHCs may not be viable in the long term. At the minimum, this study points to specific ways in which changes to the patient environment may impact $\mathrm{CHCs}$, and that managers and directors of CHCs should prepare for these changes by building reserves that will allow them to adapt to a potentially more competitive environment.

\section{Acknowledgements}

We would like to thank Heidi L. Allen for help in developing the initial ideas for this study, Julien Teitler and Tom D'Aunno for feedback on initial drafts of the manuscript, the late Woods Bowman for help with financial ratio calculations, three anonymous NPF reviewers for helpful comments, Phillip Tran for exceptional research assistance, Sarah Macartney for line-editing, and USD SOLES Faculty Research Grant initiative for funding support.

\section{Funding}

This work was supported by the University of San Diego, SOLES (Grant Number: Faculty Research Grant 20182019).

\section{Notes}


1 While the health care market is not a pure competitive market as information asymmetries exists and prices are not based on demand but rather negotiated and established centrally among government agencies and managed care organizations, health care organizations nevertheless are influenced by competitive market forces that may impact costs and service quality.

2 In addition to managerial tactics, Galaskiewicz and Bielefeld (1998) also outline political and retrenchment tactics and each of these three tactics can also be internal or externally focused (see Table 1.1, p. 10).

3 Bowman's (2011) "return on assets" is a slight variation on Tuckman and Chang's (1991) "margin" measure in that Bowman divides "change in net assets" over total assets rather than total revenue. Similarly, Greenlee and Bukovinsky's (1998) "savings indicator" is calculated by dividing "change in net assets" over "total expenses."

4 For current list of states the require CON, please see: http://www.ncsl.org/research/health/con-certificate-of-need-state-laws.aspx (accessed June 2019).

5 Twenty-eight "administrative" and "administrative/service delivery" sites were identified in San Diego County from the HRSA data warehouse (https://data.hrsa.gov/data/download) (accessed February 2019). Employee Identification Numbers (EIN) were gathered from Guidestar. Overall, 25 of the $28(89 \%)$ of the centers listed in the HRSA database were matched with the organizations in the CORE trend file via EINs in San Diego County.

$6 \mathrm{http}: / /$ datawarehouse.hrsa.gov/tools/dataportal.aspx (downloaded October 2014).

7 We thank Woods Bowman for suggesting this alternative measure (email correspondence, September 26, 2014).

8 GMM models rely on STATA xtabond2 command developed by Roodman. These use feasibly efficient two-step estimation with Windmeijer (2005) corrected standard errors, which is: asymptotically efficient, and robust to heteroskedasticity, non-sphericity of error terms, correlation between unit-specific effects and time invariant characteristics, and omitted-variable bias (Hsaio 2014, 99-101; 119-121; Roodman 2006, 8). The models presented instrument time-variant independent variables with all available lags in the difference equation. Time invariant variables at the county and state level are considered exogenous and instrumented in the levels equation, as are dummy variables for fiscal years (not presented below). Model results satisfy the expectations of the AB tests for autocorrelation (see significant AB1 and insignificant AB2 tests) as well as Hansen tests for the exogeneity of instruments (Hansen $>0.05$ and less than potentially problematic values near 1).

$9\left(100^{*}\left[\mathrm{e}^{\beta E X P A N S I O N}-1\right] /\left\{1-\beta \mathrm{MARGINS}_{\mathrm{T}-1}\right)\right.$.

10 These models were confirmed by fixed effects models accounting for fixed effects at the state, county, organization, and fiscal year level (fiscal year both partial out and accounted for with dummy variables), although these models are vulnerable to Nickell bias due to serial correlation in the dependent variable.

11 We caution against interpreting these results as a prescriptive finding regarding $\mathrm{CHC}$ revenue management, but rather as a suggestion that CHCs with this type of revenue structure are likely to generate fewer net assets, as we do not model organizations' capacity to capture any sources of revenue or the expenses that correspond with these revenue sources.

\section{References}

Allard, Scott W., and Steven R. Smith. 2014. "Unforeseen Consequences: Medicaid and the Funding of Nonprofit Service Organizations." Journal of Health Politics, Policy and Law 39, no. 6 (December): 1135-72.

Allen, Heidi, Ashley Swanson, Jialan Wang, and Tal Cross. 2017. “Early Medicaid Expansion Associated With Reduced Payday Borrowing In California." Health Affairs 36 (10): 1769-76.

Alvarez, C., P. Lantz, P. Sharac, and P. Shin. 2015. “Food Insecurity, Food Assistance and Health Status in the U.S. Community Health Center Population." Journal of Health Care for the Poor and Underserved 26 (1): 82-91.

Antonisse, Larisa, Rachel Garfield, Robin Rudowitz, and Samantha Artiga. 2018. “The Effects of Medicaid Expansion under the ACA: Updated Findings from a Literature Review." Kaiser Family Foundation.

Bailey, Martha J., and Andrew Coodman-Bacon. 2015. "The War on Poverty's Experiment in Public Medicine: Community Health Centers and the Mortality of Older Americans." American Economic Review 105 (3): 1067-104.

Bazzoli, Cloria J., Naleef Fareed, and Teresa M. Waters. 2014. “Hospital Financial Performance In The Recent Recession And Implications For Institutions That Remain Financially Weak." Health Affairs 33 (5): 739-45.

Bigelow, Barbara, and Melissa M. Stone. 1995. “Why Don't They Do What We Want? An Exploration of Organizational Responses to Institutional Pressures in Community Health Centers." Public Administration Review 55, no. 2 (March/April): 183-92.

Bowman, Woods. 2011. Finance Fundamentals for Nonprofits: Building Capacity and Sustainability. New Jersey: John Wiley \& Sons, Inc.

Bruen, Brian K., Leighton Ku, Xiaoxiao Lu, and Peter Shin. 2013. “No Evidence That Primary Care Physicians Offer Less Care To Medicaid, Community Health Center, Or Uninsured Patients." Health Affairs 32 (9): 1624-30.

Calabrese, Thad. 2012. "The Accumulation of Nonprofit Profits: A Dynamic Analysis." Nonprofit and Voluntary Sector Quarterly 41 (2): $300-24$.

Calabrese, Thad. 2013. "Running on Empty: The Operating Reserves of U.S. Nonprofit Organizations." Nonprofit Management \& Leadership 23, no. 3 (March): 281-302.

Cantor, Joel C., Alan C. Monheit, Derek DeLia, and Kristen Lloyd. 2012. "Early Impact of the Affordable Care Act on Health Insurance Coverage of Young Adults." Health Services Research 47, no. 5 (October): 1773-90.

Chokshi, Dave A., Ji E. Chang, and Ross M. Wilson. 2016. "Health Reform and the Changing Safety Net in the United States." The New England Journal of Medicine 375, no. 18 (November): 1790-96.

Clemenson, Barbara, and R. Drew Sellers. 2013. "Hull House: An Autopsy of Not-for-profit Financial Accountability." Journal of Accounting Education 31 (3): 252-93.

DeVoe, Jennifer E., Miguel Marino, Rachel Cold, Megan J. Hoopes, Stuart Cowburn, Jean P. O’ Malley, John Heintzman, et al. 2015. “Community Health Center Use After Oregon's Randomized Medicaid Experiment." Annals of Family Medicine 13, no. 4 (July/August): 312-20.

Doonan, Michael, and Cabrielle Katz. 2015. “Choice in the American Healthcare System: Changing Dynamics under the Affordable Care Act." Current Sociology Monograph 63 (5): 746-62.

Evans, Christopher S., Sunny Smith, Leslie Kobayashi, and David C. Chang. 2015. "The Effect of Community Health Center (CHC) Density on Preventable Hospital Admissions in Medicaid and Uninsured Patients." Journal of Health Care for the Poor and Underserved 26, no. 3 (August): 839-51. 
Felland, Laurie E., Cara S. Lesser, Andrea B. Staiti, Aaron Katz, and Patricia Lichiello. 2003. "The Resilience of the Health Care Safety Net, 1996-2001." Health Services Research 38, no. 1 Part II (February): 489-502.

Fiscella, Kevin, and H. Jack Ceiger. 2014. “Caring for the Poor in the twenty-first Century: Enabling Community Health Centers for a New Era." Journal of Health Care for the Poor and Underserved 25, no. 4 (November): 2044-52.

Froelich, Karen A., Terry W. Knoepfle, and Thomas H. Pollak. 2000. "Financial Measures in Nonprofit Organization Research: Comparing IRS 990 Return and Audited Financial Statement Data." Nonprofit and Voluntary Sector Quarterly 29, no. 2 (June): 232-54.

Galaskiewicz, Joseph, and Wolfgang Bielefeld. 1998. Nonprofit Organizations in an Age of Uncertainty. New York: Aldine de Gruyter.

Hager, Mark A. 2001. "Financial Vulnerability among Arts Organizations: A Test of the Tuckman- Chang Measures." Nonprofit and Voluntary Sector Quarterly 30 (2): 376-92.

Han, Xinxin, Qian Luo, and Leighton Ku. 2017. "Medicaid Expansion And Grant Funding Increases Helped Improve Community Health Center Capacity." Health Affairs 36, no. 1 (January): 49-56.

Henderson, Tim, and Anne R. Markus. 1996. “Medicaid Managed Care: How Do Community Health Centers Fit?" Health Care Financing Review 17, no. 4 (Summer): 135-42.

Henry, Lisa. 2015. "Physician Assistants, Nurse Practitioners, and Community Health Centers under the Affordable Care Act." Human Organization 74, no. 1 (Spring): 42-51.

Hoopes, Megan ]., Heather Angier, Rachel Cold, Steffani R. Bailey, Nathalie Huguet, Miguel Marino, and Jennifer E. DeVoe. 2016. “Utilization of Community Health Centers in Medicaid Expansion and Nonexpansion States, 2013-2014." Journal of Ambulatory Care Management 39, no. 4 (October-December): 290-98.

Hsaio, Cheng. 2014. Analysis of Panel Data, 3rd ed. New York: Cambridge University Press.

Huguet, Nathalie, Megan ]. Hoopes, Heather Angier, Miguel Marino, Heather Holderness, and Jennifer E. DeVoe. 2017. "Medicaid Expansion Produces Long-Term Impact on Insurance Coverage Rates in Community Health Centers." Journal of Primary Care \& Community Health 8 (4): 206-12.

Janet. S., Greenlee, and David Bukovinsky. 1998. "Financial Ratios for Use in the Analytical Review of Charitable Organizations." The Ohio CPA Journal 57 (1): 32-38.

Kaiser Family Foundation. 2017. "Community Health Centers: Recent Growth and the Role of the ACA." Issue Brief (January): 1-13.

Kaiser Family Foundation. 2018. "The Effects of Medicaid Expansion under the ACA: Updated Findings from a Literature Review." Issue Brief (March): 1-36.

Kaiser Family Foundation. 2019. "Status of State Action on the Medicaid Expansion Decision." Accessed May, 2019. https://bit.ly/2ApqilS

Katz, Aaron B., Laurie E. Felland, lan Hill, and Lucy B. Stark. 2011. "A Long and Winding Road: Federally Qualified Health Centers, Community Variation and Prospects under Reform." Center for Studying Health System Chagen, Research Brief, no. 21 (November): 1-9. https://www.issuelab.org/resources/13080/13080.pdf.

Knowlton, Lisa M., Arden M. Morris, Lakshika Tennakoon, David A. Spain, and Kristan L. Staudenmayer. 2018. “Financial Stability of Level I Trauma Centers within Safety-Net Hospitals." Journal of American College of Surgeons 227: 172-80.

Kotelchuck, Ronda, Daniel Lowenstein, and Jonathan N. Tobin. 2011. “Community Health Centers and Community Development Financial Institutions: Joining Forces to Address Determinants of Health." Health Affairs 30, no. 11 (November): 2090-97.

Ku, Leighton, Emily Jones, Peter Shin, Fraser R. Byrne, and Sharon K. Long. 2011. "Safety-net Providers after Health Care Reform: Lessons from Massachusetts." Archives of Internal Medicine 171 (15): 1379-84.

Lam, M., and L. McDougle. 2016. "Community Variation in the Financial Health of Human Service Nonprofits: An Examination of Organizational and Contextual Effects." Nonprofit and Voluntary Sector Quarterly 45 (3): 500-25.

McAlearney, John S. 2002. "The Financial Performance of Community Health Centers, 1996-1999." Health Affairs 21, no. 2 (March/April): 21925.

Miller, Sarah, and Laura R. Wherry. 2017. "Health and Access to Care during the First 2 Years of the ACA Medicaid Expansions." The New England Journal of Medicine 376 (March): 947-56.

National Association of Community Health Centers (NACHC). 2013. "A Sketch of Community Health Centers." Chart Book. Available at: http://www.nachc.com/client/Chartbook2013.pdf.

Noh, Shihyun, and Catherine H. Brown. 2018. “Factors Associated with the Number of Substance Abuse Nonprofits in the U.S. States: Focusing on Medicaid Expansion, Certificate of Need, and Ownership." Nonprofit Policy Forum. De Gruyter: 1-11.

Roodman, David. 2006. "How to Do Xtabond2: An Introduction to "difference" and "system" CMM in Stata." Center for Clobal Development: Working Paper Number 103. https://papers.ssrn.com/sol3/papers.cfm?abstract_id=982943.

Schauffler, Helen H., and Judith Wolin. 1996. "Community Health Clinics Under Managed Competition: Navigating Uncharted Waters." Journal of Health Politics, Policy and Law 21 (3): 461-88.

Shea, Matthew, and Robert D. Hamilton. 2015. “Who Determines How Nonprofits Confront Uncertainty?” Nonprofit Management \& Leadership 25, no. 4 (Summer): 383-401.

Sommers, Benjamin D., Emily Arntson, Genevieve M. Kenney, and Arnold M. Epstein. 2013. “Lessons from Early Medicaid Expansions Under Health Reform: Interviews with Medicaid Officials." Medicare \& Medicaid Research Review 3 (4): 1-19.

Sommers, Benjamin D., and Arnold M. Epstein. 2013. "U.S. Covernors and the Medicaid Expansion — No Quick Resolution in Sight." New England Journal of Medicine 368, no. 6 (February): 496-99.

Taubman, Sarah L., Heidi L. Allen, Bill J. Wright, Katherine Baicker, and Amy N. Finkelstein. 2014. “Medicaid Increases EmergencyDepartment Use: Evidence from Oregon's Health Insurance Experiment." Science 343 (6168): 263-68.

Tuckman, Howard P., and Cyril F. Chang. 1991. "A Methodology for Measuring the Financial Vulnerability of Charitable Nonprofit Organizations." Nonprofit and Voluntary Sector Quarterly 20 (4): 445-60.

Walker, Melissa A., and Jason E. Osterhaus. 2010. "Medicaid Fee for Service Reimbursement and the Delivery of Human Services for Individuals with Developmental Disabilities or Severe Mental Illness: Negotiating Cost." Journal of Health and Human Services Administration 32, no. 4 (Spring): $380-404$ 
Windmeijer, Frank. 2005. "A Finite Sample Correction for the Variance of Linear Efficient Two-step GMM Estimators." Journal of Econometrics 126 (1): 25-51. 